\title{
Assessment of Suspected Dementia
}

\author{
H. Chertkow, H. Bergman, H.M. Schipper, S. Gauthier, R. Bouchard, S. Fontaine, \\ A.M. Clarfield
}

\begin{abstract}
At the Second Canadian Consensus Conference on Dementia (CCCD) (February, 1998), a group of neurologists, geriatricians, and psychiatrists met to consider guidelines for evaluation of dementia in Canada. This review paper formed a background paper for their discussion of dementia diagnosis. These experts from across the country concluded that diagnosis of suspected dementia cases continued to rest on skilled clinical assessment. Mental status exam, preferably in some quantifiable form, has become an essential part of the assessment. Selected laboratory tests are advisable in all cases (CBC, TSH, electrolytes, calcium, and glucose), but the CCCD continued to advise that CT scanning was mandatory only in selected cases where clinical findings pointed to another possibility besides Alzheimer's disease. The growing list of other diagnostic measures with potential usefulness in diagnosis of Alzheimer's disease or dementia in general was reviewed, but the evidence was judged as insufficient to support routine use of these tests by physicians. As new treatments for Alzheimer's disease become available, neurologists face new diagnostic challenges - differentiating Mild Cognitive Impairment, Frontotemporal dementias and Mixed dementias, and Lewy Body Dementia. Guidelines to aid in differential diagnosis are presented.
\end{abstract}

RÉSUMÉ: Évaluation du patient chez qui on soupçonne la présence d'une démence. Lors de la deuxième Conférence canadienne de consensus de la démence (CCCD) (février 1988), un groupe de neurologues, de gériatres et de psychiatres se sont rencontrés pour élaborer des lignes directrices pour l'évaluation de la démence au Canada. Cet article de revue a servi d'article de fond pour leur discussion du diagnostic de la démence. Ces experts de tous les coins du pays ont conclu que le diagnostic chez les patients chez qui on soupçonne une démence demeure basé sur une évaluation clinique attentive. L'examen de l'état mental, préférablement sous forme quantifiable, est devenu une partie essentielle de l'évaluation. Certaines épreuves de laboratoire sont conseillées dans tous les cas (hémogramme complet, concentrations de TSH, électrolytes, calcium et glucose), mais la CCCD a maintenu la recommandation que la tomodensitométrie cérébrale n'est requise que dans les cas où l'évaluation clinique laisse soupçonner la possibilité d'un diagnostic autre que celui de maladie d'Alzheimer (MA). Une liste sans cesse croissante d'épreuves diagnostiques pouvant être utiles dans le diagnostic de la MAou de la démence en général a été révisée, mais on a considéré que l'évidence était insuffisante pour supporter l'utilisation de routine de ces tests par les médecins. À mesure que des traitements nouveaux de la MA deviennent disponibles, les neurologues font face à de nouveaux défis diagnostiques - le diagnostic différentiel de la dysfonction cognitive légere, des démences fronto-temporales et des démences mixtes, et de la démence associée à la maladie des corps de Lewy. Des lignes directrices pour aider au diagnostic différentiel sont présentées.

Can. J. Neurol. Sci. 2001; 28: Suppl. 1 - S28-S41

\section{THE SPECTRUM OFAGING AND COGNITION}

\section{Normality}

There is a spectrum of memory ability found in the elderly (Figure). Rarely one encounters elderly individuals whose memory capacity exceeds that of younger patients. Unfortunately, these "supernormal" active elderly make up only about $5 \%$ of elderly populations. ${ }^{1}$ More commonly, elderly individuals note a decline compared to their previous performance at a younger age. ${ }^{2,3}$ Most commonly noted changes include difficulty in simultaneously attending to multiple sensory inputs (e.g. listening to the radio while writing a letter) and problems recalling proper names of occasional acquaintances. Formal neuropsychological tests will additionally reveal a decline in performance on delayed verbal memory tests and slowing of processing speed. These are often referred to as aspects of fluid intelligence. Other aspects of cognition - e.g. vocabulary and general knowledge - in fact generally increase

From the Bloomfield Centre for Research in Aging, Lady Davis Institute, Dept. of Clinical Neuroscience, and Dept. of Medicine, SMBD-Jewish General Hospital, McGill University (HC, HS, HB), Division of Geriatric Medicine, Dept. of Medicine, McGill University (HB, HC, HS), Division of Geriatric Medicine, Dept. of Medicine, SMBD-Jewish General Hospital (HC, HB, MC, HS), Research Centre, Institut Universitaire de Gériatrie de Montréal, (HC), McGill Centre for Studies in Aging, McGill University (HC, SG), Professeur agrègè de clinique (neurologie), Université Laval (RB), Dept. of Radiology, Neurology, and Neurosurgery, Montreal Neurological Hospital, McGill University (SF), Montreal, QC Canada, and Sarah Herzog Hospital, Jerusalem, Israel (MC).

Reprint requests to: H. Chertkow, Bloomfield Centre for Studies in Aging, Lady Davis Institute, 3755 Cote Ste. Catherine Road, Montreal, QC Canada H3T1E2 


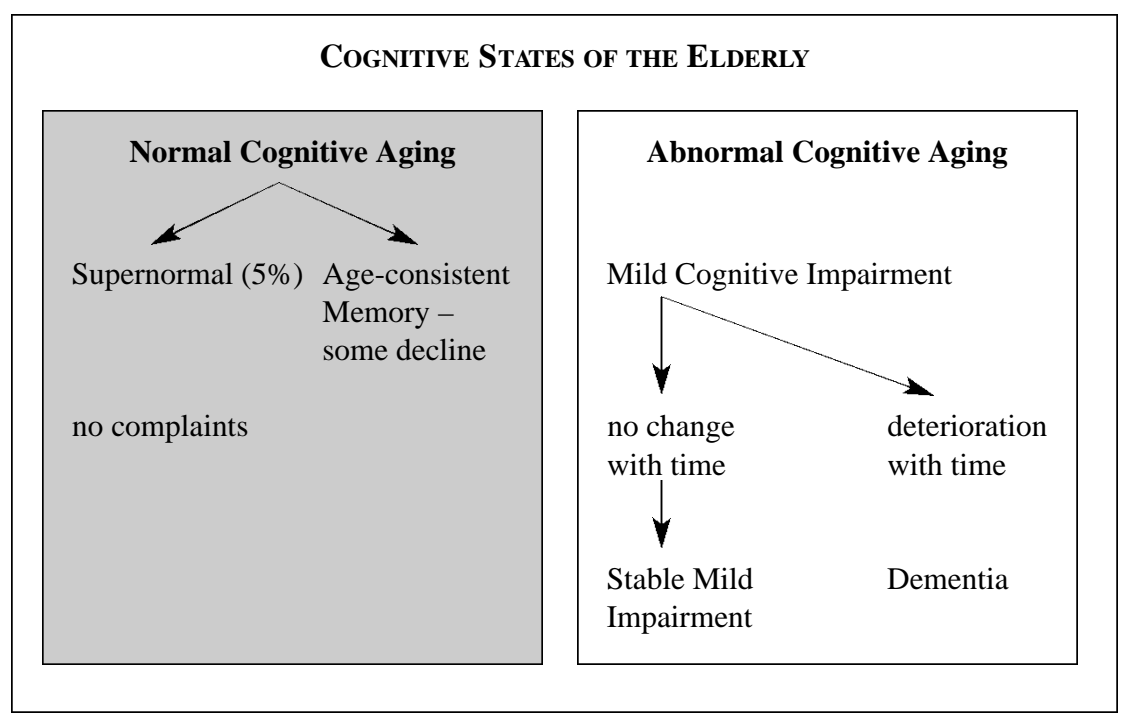

Figure: Cognitive subgroups of the elderly

with age. All of these changes would now be classified as being part of normal aging. ${ }^{4}$ While occasionally of concern to patients, these alterations are of no particular prognostic significance.

We view these changes in cognitive aging as a normal phenomenon. Such changes may parallel histologic brain alterations (e.g. atrophy and the increase in senile plaques with age), and physiologic phenomena (such as EEG slowing with age) which do not alone indicate brain abnormality. These changes underline the basic idea that elderly individuals should be considered in comparison to a group of age-matched subjects, not compared to the performance of younger subjects. ${ }^{5}$

\section{Mildly abnormal cognitive aging}

Certain elderly individuals manifest mild memory loss both subjectively and on objective formal testing. These are the patients who usually complain (and some of whose families complain) that their memory function has deteriorated over recent years, yet they have not reached the point where this is interfering with daily function. In many cases, this degree of impairment is insufficient to attach a clear diagnosis of dementia. In the Canadian Study of Health and Aging (CSHA), the term CIND (Cognitive Impairment, No Dementia), was applied to this group of individuals, who accounted for $16.8 \%$ of subjects over age $65 .{ }^{6}$ About $1 / 3$ of this group (about 167,000 Canadians) formed a subgroup of CIND, termed "Circumscribed Memory Impairment", who had no obvious cause for their cognitive problems. A number of labels have been attached to such persons over the years, including benign senescent forgetfulness, ${ }^{7}$ late life forgetfulness, ${ }^{2}$ age-associated memory impairment (AAMI), ${ }^{8}$ "questionable dementia",, 10 aging-associated cognitive decline (AACD) ${ }^{11}$ and mild cognitive impairment (MCI). ${ }^{12}$ These patients all represent mixed groups containing individuals with very different prognoses. Some patients with such mild memory loss may represent the extreme of the distribution of changes seen in normal aging. Other patients within this heterogenous group have a benign condition which does not progress to dementia over longitudinal follow-up, although the mild cognitive impairment may be quite upsetting to the patients. At the same time, some of the patients in this group are in the earliest stages of dementia and will decline with longitudinal follow-up. The dementia may be degenerative, or at times, even vascular in origin. ${ }^{13}$

It is difficult to generalize about this group of individuals, since there is no agreed upon taxonomy or classification. All researchers agree that MCI individuals should show subjective as well as objective impairment in memory, representing a decline from their previous level of function. In Europe, the term MCI is taken to include individuals who show impairment on tests of complex function. ${ }^{14}$ In the United States, MCI implies no loss of function but merely objective memory loss of over 1.5 standard deviations below the age-adjusted mean on objective memory tests. ${ }^{15}$ The prognosis depends on severity of memory loss and over-all impairment; a study in Boston found that $19 \%$ of MCI subjects deteriorated to dementia over a three year follow-up. ${ }^{16}$ O'Connor et al $^{17}$ followed a similar set of mildly impaired patients and found that $50 \%$ had progressed to dementia after two year follow-up. Chertkow et $\mathrm{al}^{18}$ found a similarly high rate of progression. Progression rates for AAMI are substantially lower. ${ }^{19}$ In a large sample with a mean age of 77, Hogan and Ebly ${ }^{19 a}$ found that, depending on which definition and criteria were used, the percentage surviving with dementia at five years follow-up varied from $21 \%$ (for AAMI) to $51 \%$ (for MCI criteria). This compares with a dementia prevalence of $14 \%$ for those judged "normal" cognitively five years earlier. Hence, different researchers hold strikingly different views on the "meaning" of an MCI label. Morris and colleagues ${ }^{20}$ view it as an earlier stage of Alzheimer's disease (AD) predicting that anyone who "falls off" the normal aging curve will eventually develop AD. Ritchie and colleagues ${ }^{13,21}$ find a much more benign prognosis in population studies. Furthermore, if dementia ensues there is a good chance it might fit a "vascular dementia" or mixed dementia label rather than AD.

There are no simple, reliable means of predicting which MCI subjects will deteriorate. History gathering aids in prognostica- 
tion but, to a limited degree only. Daly et $\mathrm{al}^{16}$ found that global ratings of severity of impairment (the sum of boxes on the Clinical Dementia Rating scale) strongly predicted the likelihood of progression; very mild individuals didn't progress, whereas more impaired subjects did. Increased age over 80 years and lower Mini-Mental State Exam (MMSE) have been identified as risk factors for progression ${ }^{19}$. The family's reporting that the patient's memory is worse than it was one year earlier and that there has been some effect on day-to-day function is also worrisome. ${ }^{22-24}$ Minimally impaired patients with purely subjective memory problems have a much lower rate of decline than groups defined by the presence of objective changes on MSE in addition to subjective memory impairment. ${ }^{3,25,26}$ Clear diagnosis and prognostication of such patients remains highly challenging. In a recent three year follow-up of 90 such individuals, there were no reliable simple clinical prognostic indicators. ${ }^{27,28}$ One intriguing finding was that orientation was a useful prognostic marker - any MCI individual who showed disorientation to time (more than just the exact hour of the interview or a one day margin of error on the date) had a strong chance of progressing to dementia on three year follow-up. This finding was specific, but not very sensitive. ${ }^{29}$ MMSE (or other mental status tools) cutoff scores are unlikely to be an aid in MCI individuals. Petersen ${ }^{12}$ found that objective failure on neuropsychological tests of delayed verbal memory, and presence of one or more apolipoprotein APO E4 alleles, increased the likelihood of progression. This requires confirmation. Clinicians should, therefore, be conservative in predicting dementia in MCI patients; it is preferable to follow patients longitudinally to improve one's ability to separate out early dementia from benign memory loss. Neurologists should be encouraged to initially equivocate in the diagnosis of such individuals. There are no adequate data available on the efficacy of instituting neuroprotective interventions in such patients (e.g., vitamin $\mathrm{E}$ use to prevent progression to dementia) although trials with donepezil and rivastigmine are currently underway. MCI subjects should be referred to centres involved in such trials. Cholinesterase inhibitors are not currently approved for treatment of MCI. Clearly the MCI stage/syndrome/diagnosis is an important area for future research.

\section{Dementia}

The far end of the spectrum of "cognitive states in the elderly" is dementia, present in $8 \%$ of the Canadian population over age 65 in the CSHA. ${ }^{30,31}$ Dementia is defined as a global deterioration in cognitive function in the setting of a clear sensorium, which distinguishes it from focal cognitive deficits such as aphasia, global deficits which are life-long such as mental retardation and global impairment of cognition producing stupor or delirium which is an acute process. ${ }^{32}$ The DSM-IV criteria (Table 1) for AD demand not only memory loss but other cognitive impairments, such as language changes or disturbed abstraction and planning ability. The presence of cognitive impairments severe enough to cause significant impairment in social or occupational performance is necessary in order to make the diagnosis. Technically, a diagnosis of dementia cannot be made unless functional impairment is recorded. In patients with previously marginal functional activity, or no family members to provide ancillary information, documenting clear functional

\section{Table 1: DSM-4 Criteria forAlzheimer's Disease}

A. The development of multiple cognitive deficits manifested by both:

1) memory impairment (inability to learn new information and to recall previously learned information)

2) at least one of the following cognitive disturbances:

a) aphasia (language disturbance)

b) apraxia (inability to carry out motor activities despite intact motor function)

c) agnosia (failure to recognize or identify objects despite intact sensory function)

d) disturbance in executive functioning (i.e. planning, organizing, sequencing, abstracting)

B. The course is characterized by gradual onset and continuing cognitive decline.

C. The cognitive deficits cause significant impairment in social or occupational functioning and represent a significant decline from a previous level of functioning.

D. The cognitive deficits in A are not due to any of the following:

1) central nervous system conditions that cause progressive deficits in memory and cognition (e.g. cerebrovascular disease, Parkinson's disease, Huntington's disease, subdural hematoma, normal pressure hydrocephalus).

2) systemic conditions that are known to cause dementia (e.g. hypothyroidism, vitamin B12 or folic acid deficiency, niacin deficiency, hypercalcemia, neurosyphilis, HIV infection).

3) substance-induced conditions

E. The deficits do not occur exclusively during the course of Delirium.

F. Not better accounted for by another Axis I disorder (e.g. Major Depressive Disorder, Schizophrenia).

impairment is a real challenge for the physician. There is no simple replacement for an extended interview with spouse or family members regarding "Instrumental Activities of Daily Living" - ability to independently shop, travel, use the phone, take care of finances, along with social activities and hobbies. Formal instruments which measure functional disability exist and can be administered by nonmedical personnel to aid this assessment. $^{33-35}$

Table 2: Occurrence of reversible dementias

\section{Electronicn permission not granted}

Adapted with permission from Clarfield A.M. The reversible dementias: Do they reverse? Ann Intern Med 1988;109:476-486. 
Dementia is an abnormal condition which requires prompt diagnosis and intervention. It has become clear that use of different criteria can alter the diagnosis of dementia strikingly when it is mild ${ }^{36,37}$ but are in fair agreement when dementia is more advanced.

\section{DifFERENTIAL DiagnOSES}

\section{Reversible dementias}

The main causes of reversible dementia have been found to be overuse of certain medications, depression and normal pressure hydrocephalus. Other causes include subdural hematoma and hypothyroidism. The frequency of encountering a truly reversible dementia has been considerably debated over the past 20 years. Wells ${ }^{38}$ used a figure of $20 \%$ of dementia cases as "potentially reversible". Clarfield ${ }^{39}$ carried out a detailed evaluation of studies estimating prevelance of reversible dementia. He concluded that partly or completely reversible causes made up $11.6 \%$ of all cases but in those studies which followed up their patients, fully reversible dementia was encountered in only $3 \%$ of cases (Table 2). Partially reversible dementia occurred in $8 \%$ of cases. Clarfield suggested that the true incidence of reversible dementias in the community is even lower than that reported and subsequent reports have confirmed this prediction. For example, a mini-meta-analysis ${ }^{40}$ of two community based studies ${ }^{41,42}$ found that only $4.2 \%$ of community-dwelling demented had even a potentially reversible cause for the cognitive decline. Assuming even a $100 \%$ recovery rate, (an extremely unlikely event) this offers a much lower rate than Clarfield's figure of $11 \%$. Weytingh et $\mathrm{al}^{43}$ describe the fascinating phenomenon wherein the percentage of both partial and full reversal of dementia fell gradually between the years 1975-90, attributing this decline to the inclusion of less selective outpatient settings and more critical diagnostic panels. They conclude that "the very low percentages of reversible dementia in recent studies are probably closer to "the truth" than those of earlier studies". More recent work from the same setting ${ }^{44}$ found that in elderly patients' referral to a Dutch memory clinic, the prevalence of reversible dementia was of the order of $1 \%$. In conclusion, Clarfield suggested that the cost-effectiveness of a dementia work-up should be weighed against the likelihood of finding such rare reversible cases.

\section{Causes of nonreversible dementia without motor features}

The differential diagnosis of nonreversible dementias has been a topic of considerable recent interest, and the discussion below is far from complete. For recent reviews of the subject, see references 45-48. While the older concept of "cortical" versus "sub-cortical" dementia is anatomically inaccurate, it is useful to approach these dementias as those lacking accompanying motor abnormalities (AD, and frontotemporal dementia) or demonstrating accompanying motor abnormalities (most of the other causes of dementia). The major cause of nonreversible dementia overall is $A D$, accounting in most series for $55-65 \%$ of all cases. ${ }^{49}$ While different diagnostic criteria have been established, there is general concordance between diagnosis of $\mathrm{AD}$ in advanced cases (see Table 1). ${ }^{32,50}$ The second most common cause, accounting for $20-30 \%$ of cases is vascular dementia. In a good number of cases, $\mathrm{AD}$ and vascular dementia coexist, and this is termed mixed dementia, which represents in most studies the third most common category. The exact proportion of dementia cases in the next two categories frontotemporal dementia (FTD) and dementia with Lewy bodies (DLB) - remains controversial. In some series, FTD accounts for $10 \%$ of the dementias, and DLB accounts for up to $20 \%$ of cases. In the tertiary care Memory Clinic at the Jewish General Hospital, each of these account for $5 \%$ of the new dementia cases seen annually.

Focal degenerative disorders of the brain can produce distinctive forms of dementia without motor features. ${ }^{51-55}$ Frontotemporal dementia is the currently accepted broad term encompassing what would have been called Pick's disease, frontal dementia, along with primary progressive aphasia and semantic dementia. As a set, these syndromes are characterized by prominent early behavioral changes or language changes with relative sparing of memory. ${ }^{55}$ Core diagnostic features include loss of personal hygiene, disinhibition and loss of social awareness, impulsivity and loss of behavioral control. ${ }^{56,57}$ There should be insidious onset and slow progression, and a family history may be present in about $45 \%$ of cases. ${ }^{58}$ There are often accompanying affective changes - depression, anxiety, delusions. Sub-forms exist with prominent naming problems and loss of semantic memory of concepts (semantic dementia), progressive reduction of speech leading to mutism (progressive aphasia), as well as a more purely frontal form with more marked attentional and executive function impairment. ${ }^{59}$ There may be associated prominent frontal lobe release signs, early incontinence, and even associated parkinsonism and corticospinal signs. At the same time, early on in their course, the major locus of dysfunction appears to be orbitofrontal cortex, and more dorsolateral frontal capacities (working memory, planning tasks) are preserved. ${ }^{60}$ MRI and SPECT demonstrate, often, abnormalities largely limited to the frontal lobes, or (for PPA) the left perisylvian cortex. ${ }^{61}$ To complicate matters, clinical-pathological correlations are heterogeneous, with pathological changes varying from classical Pick's disease, to Pick Complex without Pick bodies, to dementia lacking distinctive pathology. Some of the typical patients are still found to have $\mathrm{AD}$ pathologically. Others go on to develop florid amyotrophic lateral sclerosis with its accompanying pathological changes. ${ }^{62}$

\section{Subcortical dementia (dementias with motor features)}

Subcortical dementia is a somewhat out-dated descriptive category referring to a heterogeneous set of vascular and degenerative diseases. At one time it was argued that such patients had a dementia with quite different features from the cortical dementias such as AD. Further evaluation has revealed that for the most part, the memory characteristics in subcortical dementia show marked overlap with cortical dementias. ${ }^{63}$ The most notable differentiation is due to noncognitive features. Patients with subcortical dementia manifest abnormalities of movement in general and the extrapyramidal system in particular. They show a stooped posture, slowing of gait, psychomotor retardation, and motor apathy. Some clinicians advocate distinguishing simply "dementia without motor abnormalities" from "dementia with motor abnormalities". ${ }^{64,65}$

The definition and spectrum of vascular dementia remains 
controversial, and has been recently reviewed. ${ }^{65-69}$ Patients with multi-infarct dementia from vascular disease are more likely to have cardiovascular disease, focal neurological signs, a history of hypotension, acute onset of symptoms, motor speed abnormalities and depression. They account for about $10 \%$ of patients with dementia. ${ }^{70}$ The ischemic score of Hachinski captures many of these elements. ${ }^{71,72}$ In a good number of cases, $\mathrm{AD}$ and vascular dementia coexist and this is termed Mixed Dementia. Increasingly sensitive neuroimaging has augmented the number of cases in which a contributing element of vascular dementia is suspected. ${ }^{73}$ Moreover, the influence of vascular factors on the natural history and severity of $\mathrm{AD}$ is becoming evident; in the Nun's study, elderly women (all of whom pathologically met criteria for AD at postmortem exam), had poorer cognition and a greater prevalence of dementia if they also had cerebral infarcts. ${ }^{74}$ In the Syst-Eur study, controlling systolic hypertension in the elderly led to as dramatic a decrease in $\mathrm{AD}$ as in vascular dementia. ${ }^{75}$ Vascular dementia is addressed in another article in this volume.

Parkinsonism in the presence of dementia continues to pose a diagnostic challenge. Parkinsonism may occur in up to $30 \%$ of $\mathrm{AD}$ patients, particularly in the later stage of the disease. ${ }^{76}$ Idiopathic Parkinson's disease can be accompanied by dementia in its later stages as well. ${ }^{77}$ Pathological evidence of cortical Lewy bodies may be found in $\mathrm{AD}$ patients, and plaques and neurofibrillary tangles are often found in the brains of Parkinsons disease patients. Nevertheless, a distinctive entity is increasingly being recognized, in which dementia and parkinsonian features emerge at about the same time, and this is now termed $D L B .^{78}$ Evaluation of the brains of DLB subjects shows that this is a distinct entity and not just a severe form of Parkinson's Disease. ${ }^{79}$ Furthermore, although AD changes may be seen in some of these brains, they seem not to affect the severity or clinical symptoms in these patients. DLB, in some series, accounts for between one and $20 \%$ of all dementias. ${ }^{78} \mathrm{~A}$ clinical diagnosis of DLB requires the presence of at least one of three core symptoms - visual hallucinations, parkinsonian signs, and markedly fluctuating cognition with variations in attention and alertness. If two or more of these criteria are present, it is "probable" DLB. The specificity of these criteria (especially if two or more of them are present) is high, over $85 \%$, while the sensitivity is $78 \% .^{80,81}$ Resting tremor is less conspicuous than rigidity and bradykinesia in these individuals. Repeated falls, sensitivity to neuroleptics, depression and delusions are often encountered. The motor abnormalities ought to have preceded the dementia by less than 12 months. DLB patients may well be responsive to cholinesterase inhibitors and so the diagnosis has therapeutic implications. ${ }^{81}$ At the same time, the variability of symptoms and difficulty in operationalizing items such as "fluctuations" results in rather poor inter-rater reliability in this clinical diagnosis - as low a $34 \%$ agreement in one study. ${ }^{82}$

There are a set of "atypical parkinsonian syndromes", characterized by extra-pyramidal signs (EPS) and usually by variable dementia. An international workshop has established diagnostic criteria for progressive supranuclear palsy (PSP) ${ }^{83}$ For possible PSP, there must be gradually progressive deterioration after age 40, with either vertical supranuclear gaze palsy or both slowing of vertical saccades and prominent postural instability with falls in the first year of onset. For probable PSP, there must be all of the above - vertical supranuclear gaze palsy, slowing of vertical saccades and prominent postural instability with falls in the first year of onset. The criteria for probable PSP are highly specific. Cognitive or behavioural changes usually begin in the first year of the disease (in $52 \%$ of cases) ${ }^{84}$ but rarely begin later. While these patients often present complaining of memory problems, the motor impairment is the impressive feature. ${ }^{83}$

Rarer forms of dementia such as corticobasal degeneration and Creutzfeld-Jacob disease (CJD) are seen about once per year in our tertiary care Memory Clinic. Any case of rapidly progressive dementia accompanied by ataxia, myoclonus, or focal neurological signs should be viewed as a possible case of $C J D$. While finding of characteristic complexes on EEG and MRI imaging may support the diagnosis, the real advance in diagnosis has been the advent and availability of 14-3-3 protein testing on cerebrospinal fluid (CSF) samples (see laboratory section). ${ }^{85-87}$

Corticobasal ganglionic degeneration (CBGD) is a rare condition presenting with an akinetic-rigid atypical parkinsonian syndrome, often asymmetric. ${ }^{88}$ It is accompanied by cognitive impairment, apraxia, cortical sensory loss, and sometimes an alien limb phenomenon. Cognitive problems have hitherto been underrated, probably because published studies originated in Movement Disorders Clinics and not Memory Clinics. It is becoming increasingly apparent that, initially, many of these patients present as focal cortical dementia syndromes classified as FTD or primary progressive aphasia with motor features.$^{89}$ In one recent series nine of 13 pathologically proven CBGD patients presented with, and 12 of 13 patients eventually developed dementia. ${ }^{90}$ Marked speech disturbance presents early in the course of the disease, and speech output problems may be prominent. Notably, only four of the 13 received a premortem diagnosis of CBGD. Of the six of 13 who received a premortem diagnosis of $\mathrm{AD}$, three had some atypical features (rapid decline, notable axial rigidity, and early speech difficulty). However, the other three seemed to have rather typical AD.

\section{Pseudodementia of depression}

A number of other diagnostic problems challenge the clinician. Depression and psychiatric symptoms may produce functional impairment which is difficult to distinguish from dementia. ${ }^{91-93}$ These issues are addressed in a parallel paper in this issue (Thorpe and Groulx, pg S83).

\section{Delirium}

Delirium also can present a diagnostic challenge. Dementia is distinguished from delirium by the longer duration and unimpaired level of consciousness. However, dementia and delirium frequently overlap: delirium occurs at some point in $40 \%$ of demented hospital in-patients over age 55, and dementia subsequently in $25 \%$ of those who are nondemented but delirious on admission. ${ }^{94,95}$ Demonstration of normal attention (for instance, a preserved forward digit span of five or over) is the best bedside approach to ruling out delirium, at least in patients with only mild dementia.

\section{Other confounding problems - deafness, aphasia and psychosis}

Deafness: Deafness can contribute to an auditory comprehension disturbance. It is vital in any patient with 
suspected dementia to ensure that hearing has been assessed because correction of hearing could improve overall function. Because a defect in auditory comprehension could be mistaken by family members for a hearing problem, it is important to enquire about apparent ability to hear sounds other than speech.

Aphasia: Aphasia is defined as impairment of expression by speech, writing or signs, or impairment of comprehension of spoken or written language. Pure aphasia such as that due to cerebral infarction is not accompanied by memory loss or the other cognitive impairments seen in dementia, but it can be a frequent component of dementia. For example, anomia and auditory comprehension deficits often occur early in AD and can be the primary finding in primary progressive aphasia. ${ }^{51,96,97}$

Psychosis: It is well recognized that many dementias (e.g. AD and DLB) are frequently accompanied by delusions, hallucinations and disorganized behaviour. However, the mental status test performance of psychotic patients is disrupted by their symptoms and thus does not reflect the patient's true intellectual capacity. Primary psychotic illness with its first onset in the elderly should always raise the suspicion of an underlying dementia, particularly FTD.

\section{Clinical Approach to dementia}

\section{History}

Dementia is a clinical diagnosis requiring detailed history taking and it is ultimately based on a clinician's judgement that global intellectual deterioration has occurred. Physicians should assess the patient's current condition, medical problems, medication, alcohol and sedative use, driving and living arrangements and functional ability. "False negatives" in which the presence of dementia is missed, remain common, primarily due to failure to appreciate dementia in the setting of psychiatric illness. ${ }^{98} \mathrm{Up}$ to $80 \%$ of the normal elderly will note some deterioration in memory over time and sometimes complain of this. ${ }^{99}$ Patients with depression but no dementia may complain of subjective memory loss quite strongly, although no objective evidence of memory difficulties is found on formal testing. ${ }^{100}$ Thus, the most challenging aspect of history taking in dementia is to separate out normal aging from the early stages of a dementing process. An additional challenge in patients with extrapyramidal features, is to elicit evidence that cognitive decline has paralleled changes in mobility, and that there is marked day to day variability in severity. Both of these should be present in patients with DLB. ${ }^{81}$

Family members must be interviewed separately from the patient. One aspect of the history is to ask family members whether, in their opinion, the patient's memory is worse than it was a year earlier and whether there has been any effect on functional ability. An answer in the affirmative has been said to be strongly predictive of a diagnosis of degenerative dementia. $^{22,101}$ Evaluation of a patient's present and previous level of function (activities of daily living and instrumental activities of daily living) also require interviewing family members separately; failure to do so often results in an inadequate appreciation of the alteration that has occurred in affect and personality. A broad range of functions should be queried. We have found that the most informative questions surround changes in the ability to pay bills and manage financial affairs, changes in ability to plan meals and organize shopping, changes in ability to carry out hobbies, and changes in ability to plan trips and "outings". Documentation of a significant decline in functional abilities is an essential component of all definitions of dementia. Use of simple functional questionnaires (e.g. OARS $)^{102,103}$ allows this information to be gathered by nurses or paramedical personnel.

\section{Examination}

Evaluation of neurologic examination findings early on have indicated that the most common findings in cases of cortical dementia such as AD are, in order, presence of frontal release signs (present in 55\% of mild to moderate AD subjects), decreased olfactory sense (in 20\%), parietal sensory signs (impaired stereognosis or graphesthesia - in $22 \%$ of AD subjects), and gait disorder ("hesitant gait") early on (in 34\%). ${ }^{104}$ Decreased olfaction has repeatedly been found to separate AD from normal controls ${ }^{105,106}$ but the predictive value of this sign in a Canadian clinic remains untested. Release signs have also been found in $9 \%$ of control subjects and were deemed neither sensitive or specific. Galasko et al ${ }^{107}$ and Franssen et al ${ }^{108}$ found very similar abnormalities in other large sets of $\mathrm{AD}$ subjects compared to controls. In the mildest $\mathrm{AD}$ group, the only notable findings appeared to be increased rigidity and a glabellar tap. Again, such findings can be found in elderly normal subjects. ${ }^{109}$ The presence of EPS occurs in a subset of (primarily possible) AD subjects. While a few investigators have claimed that the presence of EPS predicts more rapid decline ${ }^{76}$ others have failed to confirm this finding. ${ }^{70,110,111}$ Overall, the main role of the neurological examination is to establish the presence of extrapyramidal and motor abnormalities suggesting an alternative, nonAlzheimer etiology such as vascular disease or DLB. Abnormalities on the neurological exam, particularly lateralizing signs can be a strong indicator of a vascular or mixed dementia. ${ }^{66,71}$

\section{Mental status testing and neuropsychological screening}

Quantification of cognitive impairment in the office or clinic is an essential part of dementia evaluation and has been the weak link in diagnosis of dementia. ${ }^{98}$ The MSE is time consuming and in practice often relies on a limited battery of memory and cognitive tests or else screening tools such as the MMSE. ${ }^{112}$ Even simple screening tests can be highly useful in that they can support the objective presence of memory impairment. For instance, very few patients who make two or fewer errors on the Folstein MMSE are found to have dementia on extensive neuropsychological testing. Similarly, ability to recall $3 / 3$ words after two minutes, ability to draw a clock correctly and ability to carry out serial seven subtractions are highly predictive of the absence of dementia. ${ }^{113}$ If there are subjective memory complaints but not objective memory loss and the individual is less than age 80, there is a low risk of either having or developing dementia over a 3.5 year follow-up. ${ }^{19}$

The Folstein MMSE is the most commonly used screening test, with a cut-off point of below 24/30 considered by Folstein to be highly suggestive of the presence of dementia. However, such a cut-off point has a low sensitivity and there may be "false positives" with the MMSE. Low education, focal brain lesions and depression can all, in the absence of dementia, result in a MMSE score below 24. ${ }^{114}$ On a neurology in-patient ward, 27\% 
of patients without cognitive impairment were found to score below $27 / 30$, and $7 \%$ of patients scored below $24 .{ }^{115}$ Recent studies suggest that no single cut-off score exists to make the MMSE a useful screening or diagnostic tool. However, in conjunction with a congruent medical history, if the MMSE score is less than 20, the likelihood of dementia presence is high. ${ }^{113}$ Similarly, if the MMSE is 26 or greater, it is highly likely that dementia is absent. Scores in between are inconclusive. Patients with AD show an annual decline on the MMSE which averages 3.4 points but there is wide variability. ${ }^{116}$ When followed over four years, $16 \%$ of $\mathrm{AD}$ subjects failed to show a decline more than three points from initial evaluation. While these limitations should be borne in mind, the Folstein represents the best available short screening tool in use. It is important to remember that language, object recognition, executive functions, visual construction abilities and a host of frontal lobe functions, are not adequately tested with the MMSE.

Investigators have recently attempted to develop short batteries of more sensitive and specific neuropsychological tests for diagnosis of dementia. Most of these have concentrated on quantitative scoring of short-term memory, ${ }^{117}$ or use of clock drawing tasks. ${ }^{118,119}$ A "seven minute screen" for dementia was published by Solomon and colleagues, ${ }^{120}$ with the claim that this short battery (including a test of time orientation,) is $100 \%$ sensitive and specific in diagnosing dementia. While intriguing in its simplicity, the battery erroneously labels many MCI individuals as already being demented. ${ }^{29}$ The test appears useful, however, in quickly indicating that an individual is no longer "normal" and more detailed evaluation is needed.

While it remains unclear whether any single neuropsychological test can prove sufficiently sensitive and specific to allow accurate diagnosis of dementia, it is probable that with the known heterogeneity of patients, the more testing which is done, the stronger the accumulated evidence of dementia becomes. In our clinic, the clinician's battery includes, in addition to the MMSE, extensive testing of delayed verbal memory, questions about past public figures and personal history (long-term memory), clock drawing, naming pictures of common and uncommon animals, questions regarding similarities and differences, verbal fluency tasks (how many animal names given in 60 seconds), and some simple problem solving. We feel that this covers most domains adequately (executive frontal functions probably less so).

Full neuropsychological testing is usually carried out by a trained psychologist or psychometrician. It can objectively clarify the degree of cognitive difficulty in borderline cases, but is expensive (and not covered under most government insurance programs), lengthy and not readily available to many clinicians. ${ }^{121}$ The "added-value" overall to dementia diagnosis resulting in a change of management is low ${ }^{122,123}$ and such testing cannot be recommended as routine in dementia diagnosis. Neuropsychological testing, however, supplies relatively objective evidence of cognitive impairment in multiple domains and is very useful in atypical or borderline cases.

\section{Laboratory investigation}

Routine laboratory investigations for dementia are necessary to rule out reversible dementias and aggravating factors. The 1989 Canadian Consensus Conference on the Assessment of
Table 3: CCCAD recommendations for lab tests

Tests recommended for all patients

CBC

TSH (thyroid stimulating hormone)

Serum electrolytes

Serum calcium

Serum glucose

Optional additional tests that may be helpful to diagnose causes of dementia

Measurement of

Ammonia

Blood gases

Drug levels

Erythrocyte sedimentation rate

Folic acid

Heavy metal levels

Serum cortisol

Serum lipids

Urea nitrogen/creatinine

Vitamin $\mathrm{B}_{12}$

Water soluble vitamins

Carotid Doppler studies

Chest radiography

Electrocardiography

Electroencephalography

Lumbar puncture

Mammography

Serologic tests for syphilis

Tests for the human immunodeficiency virus

Management of Dementing Disorders - Reprinted from, by permission of the publisher, CMAJ 1999;160 (12 Suppl);S1-15 C1999 Canadian Medical Association

Dementia (CCCAD) indicated the tests which should be done for all patients and additional tests for selected patients depending on the results of history and physical exam (Table 3). The CCCAD limited "all" patients to CBC, TSH, electrolytes, calcium, and glucose. ${ }^{124}$ Other proposed laboratory batteries have suggested, in addition, BUN and creatinine, liver function tests, B12 and folate, and syphilis serology. Corey-Bloom et al $^{125}$ also suggested routine sedimentation rate, and HIV screen (see Table 5). In a retrospective study of 119 cases by Chui and Zhang ${ }^{122}$, the laboratory testing resulted in a change of diagnosis in 11 cases (9\%), consisting of high TSH in four cases, positive MHATPin four cases, low B12 in one case, excluding metabolic causes of dementia in two others. Nevertheless, little evidence has arisen since 1991 to challenge the logic behind the original CCCAD laboratory proposals and they were reaffirmed at the second CCCD conference. ${ }^{126}$ These tests may identify metabolic or systemic causes in $1-2 \%$ of dementia cases. EEG, ${ }^{127}$ and lumbar puncture ${ }^{128}$ have limited utility in dementia diagnosis and should be restricted to special cases where seizures, chronic encephalitis or CJD are suggested by history or physical exam.

Any case of rapidly progressive dementia accompanied by 
Table 4: Conditions suggesting referral for neuroimaging

History (1) age less than 60 years

(2) use of anticoagulants and/or a history of bleeding disorder

(3) recent head trauma

(4) previous history of carcinoma (from sites that metastasize to brain - for example, lung, breast)

(5) unexplained neurological symptoms (e.g., new onset headaches, seizures)

(6) rapid unexplained decline (e.g., over 1 to 2 months) in cognition and/or functional status

(7) "short" duration of dementia ( $<2$ years)

(8) history of urinary incontinence and gait disorder early in the course of dementia, suggestive for NPH (in the latter stages of Alzheimer's disease, urinary incontinence and gait ataxia commonly occur)

(9) unusual or atypical cognitive, behavioral or neuropsychological presentation

Physical (1) localizing signs (e.g., hemiparesis, Babinski response)

(2) gait ataxia

Adapted with permission, CCAD, 1989, (and adopted at 2nd CCAD, 1998). Management of Dementing Disorders - Reprinted from, by permission of the publisher, CMAJ 1999;160 (12 Suppl);S1-15 (C1999 Canadian Medical Association

ataxia, myoclonus, or focal neurological signs should be viewed as a possible case of CJD. While finding of characteristic complexes on EEG and MRI imaging may support the diagnosis, the real advance in diagnosis has been the advent and availability of 14-3-3 protein testing on CSF samples. This normal cellular protein is expressed in a variety of tissues including neurons and is released into the CSF in the presence of rapid and extensive brain tissue destruction. False positive results are rare (we have been impressed by the lack of false positives in rapidly progressing cases of ALS, for instance) but may occur with herpes encephalitis and stroke. Sensitivity appears to be high $(97 \%)$ and specificity is adequate $(87 \%) .87,129$ The $14-3-3$ CSF protein test is now easily available through Dr. Neil Cashman's laboratory at University of Toronto, or Dr. Joe Gibb's lab at the $\mathrm{NIH}$ and is now an essential element of CJD diagnosis.

Published guidelines ${ }^{40,124,130}$ and review articles ${ }^{45,125,131}$ on the diagnosis of dementia recommend a number of specific laboratory tests, summarized in Table 6. The most recent consensus statement ${ }^{132}$ further highlights that overreliance on, and overinterpretation of, laboratory findings should be avoided. A detailed cost-analysis of the diagnostic assessment in dementia clearly showed that the human component of this process is far more cost-effective, although requiring additional investments in physicians'training and education. ${ }^{133,134}$

\section{Neuroimaging}

In most tertiary referral centres, all patients with dementia are subjected to neuroimaging to exclude tumour, mass lesions, strokes, or normal pressure hydrocephalus (NPH), and for research purposes. The American Academy of Neurology (AAN) practice parameters ${ }^{130}$ suggested that neuroimaging be considered in every patient with dementia, in order to identify potentially treatable conditions (tumors, subdurals, NPH). Nevertheless, they noted that no consensus for the need for such studies existed for patients over age 60 with an insidious course, without focal signs or symptoms, seizures, or gait disturbance. The $1989 \mathrm{CCCAD}^{124}$ had originally suggested that in primary care settings such neuroimaging could be limited to atypical cases delineated using clear guidelines, and these guidelines on referral for neuroimaging were again adopted with modification at the second CCCD conference in 1998. ${ }^{135}$

The most commonly used modality - computed tomography (CT) has a clear role in excluding rare reversible causes of dementia such as brain tumor or NPH but it is unclear that CT can distinguish AD or cortical dementias from normal aging. Since excluding treatable pathology is its major indicator, a noncontrast $\mathrm{CT}$ is adequate in most cases. While advanced $\mathrm{AD}$ is often accompanied by CTevidence of atrophy, particularly in the temporal lobes, ${ }^{136}$ in early AD CT findings are less impressive and many such patients show little atrophy unless additional slices are made of the temporal lobe, using a 20 degrees caudal angle to the canthomeatal line, in order to better visualize the mesio-temporal lobes. A recent retrospective study applied the CCCAD criteria for neuroimaging to a large cohort of memory clinic patients and found that, indeed, application of those criteria would have avoided $2 / 3$ of the scans carried out, without missing any cases of treatable pathology. ${ }^{137}$

A recent evaluation of the AAN Practice Parameters ${ }^{122}$ reached a similar conclusion. Applying the very similar AAN guidelines to 119 cases assessed in a memory clinic would have obviated neuroimaging in $1 / 3$ of the cases. In six of those cases, meaningful neuroimaging findings would have been missed. Of those, only a case of possible NPH (without incontinence or gait problems) might have led to potential reversibility. The other cases consisted of possible FTD revealed by $\mathrm{CT}$, and four cases with clinically unsuspected cerebral infarcts (hence mixed dementia rather than pure AD). Thus, there is no convincing evidence to date leading us to abandon the criteria of the 1991 consensus statement for more restricted neuro-imaging. The sensitivity of CT and MRI scan may, in the future, be increased by quantitative measures such as volumetric measurements of hippocampus or other atrophy measures. ${ }^{138-140}$ One evolving role of anatomic neuroimaging may be to aid in diagnostic and prognostic evaluation of MCI subjects. Recent evidence suggests that MCI patients with more pronounced hippocampal atrophy or greater shrinkage of focal brain areas over time have a greater chance of progressing to AD after three to five years' followup. ${ }^{141,142}$

Our understanding of vascular lesions on CT and MRI, and their relationship to dementia subtype, is evolving as new data become available. Currently, it is unclear how vascular changes on MR (or CT), unaccompanied by clinical correlates, should alter patient management. Patchy white matter lucencies or white matter changes (WMC) are seen frequently in demented subjects, particularly with use of more sensitive MRI scanning but may also been seen in up to $10 \%$ of cognitively intact elderly subjects. ${ }^{74}$ While some clinicians recommend MRI if vascular dementia is suspected, the WMC seen or $\mathrm{T}_{2}$-weighted images may be markers for hypertension and may not be related to the dementia. The finding of such white matter lucencies is thus 
compatible with normal cognition, $\mathrm{AD}$, or vascular dementia $^{143,144}$ and therefore of little use in differential diagnosis. At the same time, we are beginning to appreciate that subtle vascular lesions, sometimes unaccompanied by clear clinical "stroke" episodes, do have an impact on cognition. Nondemented subjects with vascular risk factors and WMC show defects in sustained mental concentration, slower recall and processing and difficulty in organizing material to be learned. ${ }^{145}$ Snowdon and colleagues ${ }^{74}$ found that among 61 autopsied individuals who met pathological criteria for $\mathrm{AD}$, those who, in addition, had brain infarcts, had poorer cognitive function and a higher prevalence of dementia than those without infarcts.

Functional imaging of regional cerebral blood flow using SPECT and positron emission tomography (PET) have shown reduced blood flow in temporal and parietal lobes in patients with AD. ${ }^{146,147}$ The degree of decline in cerebral blood flow in temporal and parietal lobes correlates with global measures of dementia severity but the pattern is not sufficiently sensitive for clinical utility. ${ }^{148}$ The utility of SPECT in early diagnosis of dementia is currently limited. In the Memory Clinic setting, SPECT was found in some studies to have low sensitivity and specificity, ${ }^{149}$ whereas other studies found it to be useful. ${ }^{150-152}$ Early AD patients may have unilateral defects, bilateral defects, or normal SPECT scans. SPECT may possibly have a role in distinguishing multi-infarct dementia from cortical dementia such as AD. They may also prove useful in differentiating frontal lobe dementias from AD. ${ }^{53}$ Using sophisticated quantitative analyses, it has even been suggested that SPECT can help in prognostication of MCI patients. ${ }^{153,153 a}$ In our own group studies

Table 5: Recommended laboratory tests for patients suspected of dementia

\begin{tabular}{|c|c|c|c|c|c|}
\hline & CCCAD & Rosser & AAN & Corey-Bloom & Geldmacher \\
\hline & 1991,1998 & 1994 & 1994 & 1995 & 1996 \\
\hline CAC & all & all & all & all & all \\
\hline Sed rate & & & & all & \\
\hline TSH & all & all & all & all & all \\
\hline $\mathrm{T} 4$ & & & all & & all \\
\hline Electrolytes & all & all & all & all & all \\
\hline BUN & & all & all & all & all \\
\hline Creatinine & & all & all & all & all \\
\hline Calcium & all & all & all & all & all \\
\hline Glycemia & all & all & all & & all \\
\hline ALT & & & all & all & all \\
\hline B12 & & all & all & all & all \\
\hline Folate & & all & & & \\
\hline Syphilis & & & & & \\
\hline serology & & all & all & all & all \\
\hline HIV screen & & & & all & opt \\
\hline CT head & opt* & all & opt* & all & all \\
\hline MRI brain & & opt & opt & opt & opt \\
\hline SPECT & & & opt & opt & \\
\hline PET & & & opt & opt & \\
\hline EEG & & opt & opt & opt & opt \\
\hline
\end{tabular}

all: all patients opt: optional opt*: optional with specific guidelines we have not found SPECT to be useful for prognostication in MCI individuals. ${ }^{154}$ Functional imaging cannot be routinely recommended at this time.

\section{Ancillary clinical and experimental diagnostic markers}

A growing number of other measures with potential usefulness in diagnosis of AD or dementia diagnosis in general have been proposed over the past five years (Table 6). Their role and utility in dementia diagnosis will require future evaluation. Each of these markers will have to be evaluated to see whether they are useful as sensitive general screening measures, specific measures to confirm the presence of dementia or $\mathrm{AD}$, or whether they are useful as markers in following therapy and progression of the disease. To be a satisfactory biomarker, a list of criteria (such as reliability, lack of invasiveness, clear relation to etiology of the disease, etc.) should be met. ${ }^{155}$

The most well-studied markers to date include CSF levels of tau and A-beta 42. ${ }^{155 a}$ These measures show high sensitivity and moderate specificity, but are fairly expensive, require lumbar puncture to obtain, and are not yet routinely in use in the diagnosis of AD in North America. Some promising biomarkers such as heme oxygenase-1 (HO-1) levels ${ }^{156}$ remain to be

Table 6: Ancillary tests for Alzheimer's disease diagnosis

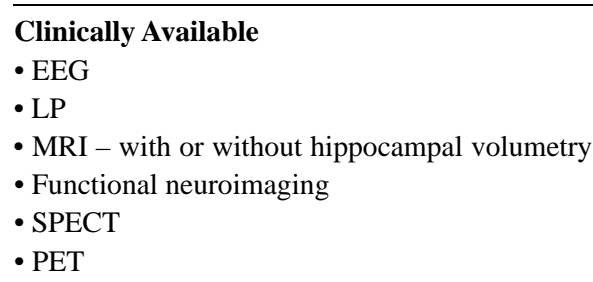

Commercial Kits Available

- APO-E genotyping (blood, Admark)

- Tau antibody (CSF, Admark)

- ß-APP42 (CSF, Admark)

- Neuronal Thread Protein (CSF, Urine, Nymox)

- genetic typing PS-1, PS-2 (blood, Admark)

\section{Experimental Measures}

Imaging

- MRI hippocampal volumes

- functional imaging (PET, SPECT)

Cognitive

- reaction time measures

- semantic priming

- computerized algorithms (e.g. CANTAB)

Neurophysiological

- EEG power spectral analysis

- cognitive evoked potentials (P300)

Neurochemical

- dilute Tropicamide eye drops (disproved)

- skin fibroblast potassium channels

Biochemical

- Blood Heme Oxygenase-1 (HO-1)

- Blood p97 
replicated by other laboratories in large groups of patients. The current ancillary tests already available and markers under investigation are listed in Table 6 . We consider that most of these markers are currently still at the experimental stage and the second CCCD conference did not recommend their routine use.

Recent data suggest that possessing an APO E4 allele can increase the risk of developing AD by age $85 .^{157,158}$ Nevertheless, the clinical role of APO-E genotyping in the diagnosis of dementia remains unclear ${ }^{157,159}$ since many individuals without E4 develop dementia, and many with E4 do not. Routine APO-E genotyping in dementia diagnosis cannot be recommended.

In families with a clear familial tendency to $\mathrm{AD}$, particularly if there is onset at a young age (before age 60), a full genetic evaluation and search for genetic markers is warranted. A University of Toronto program to collect samples from such families is currently underway.

\section{WHO SHOULD DIAGNOSE DEMENTIAAND WHAT SHOULD WE DIAGNOSE?}

The accurate diagnosis of dementia has become more complex over the past decade and the stakes have grown higher. Four sources of increased stress on neurologists and geriatricians are worth noting: 1) the number of elderly, memory-impaired individuals continue to rise ${ }^{30}$ and yet a "wait and see" approach is less acceptable to patients now that symptomatic treatment for $\mathrm{AD}$ exists, 2) physicians are being instructed to draw diagnostic distinctions they might previously have ignored (e.g. MCI vs $\mathrm{AD})$, 3) time-consuming assessment of MSE and functional assessment are being encouraged as an essential component of diagnostic assessment without any concomitant financial remuneration for the physician involved, and 4) on one hand, authorities such as the second Canadian Consensus Conference on Dementia ${ }^{135}$ insist that the initial assessment of dementia (and its treatment) should take place in a family practice setting, while on the other hand, there are serious pressures afoot that will result in increasing numbers of memory-impaired individuals being referred to neurologists and geriatricians for diagnosis and treatment. In addition to those factors already listed, one would add pressures to obtain neuroimaging more rapidly and new complex provincial government forms required for obtaining donepezil (and ultimately other effective medications) under government/insurance programs. Family physicians in Montreal have reported feeling stressed that such forms demand serial MMSE results, thorough cognitive assessment at six month intervals and are frequently rejected if a list of conditions are not satisfied. The cumulative effect is not trivial. In our tertiary care Memory Clinic at the Jewish General Hospital in Montreal, we have experienced a $100 \%$ increase in the number of referrals from family physicians over the past twelve months.

Neurologists are also experiencing new "diagnostic stress" in the wake of government-sponsored programs that specifically target $\mathrm{AD}$ and not other diagnostic categories. A patient labelled as "AD, atypical, with prominent verbal impairment" will qualify for reimbursement for donepezil under the Quebec government program. If the same patient is labelled as "Primary Progressive Aphasia", the application will be rejected. Given our limitations in clinical-pathological correlation discussed in this article, physicians may well now err towards labelling many patients as "atypical AD" in order to gain access to treatments.

\section{WHY EARLY DIAGNOSIS?}

Although some authors have suggested that all patients over 65 years old in a primary care practice should be screened for dementia, there is little evidence that this would be costeffective. Memory complaints from patients or families, however, should be considered seriously. Some have argued that early diagnosis is irrelevant or even harmful because there is no effective treatment for AD and that "harmful" labelling can occur. With the advent of cholinesterase inhibitors as effective symptomatic treatments, this position has become increasingly questionable. If any of a number of preventive therapies prove effective at delaying $\mathrm{AD}$, early diagnosis will become an even more urgent priority. Furthermore, early diagnosis can be important for other reasons. If the memory problems are due to normal aging, then the patient will be reassured. There are indications that there is a greater chance of actually successfully treating potentially reversible causes if they are discovered early. ${ }^{137}$ As well, although multi-infarct dementia is not reversible, controlling risk factors may prevent progression, although hard evidence for this benefit does not yet exist. If the dementia is irreversible, then the detection and treatment of comorbid factors will assure that the patient functions at their highest potential. Early diagnosis will also permit patients, families and health care workers to plan for the future.

\section{ConClusion}

The diagnosis of dementia is an increasingly complex process. The field of dementia has matured greatly since the original publication of the CCCAD consensus statement in 1991. An increased demand is now placed on physicians in terms of the number of persons consulting about their cognitive complaints and requesting treatment. Consideration should be given to:

1. the use of structured screening questionnaires filled out by informants with help from nonmedical personnel.

2. training of nonmedical personnel in the use of simple mental status evaluation tools such as the MMSE, and functional ability questionnaires.

3. the provincial fee schedules should be adjusted to accommodate the extended time commitment necessary to carry out a proper MSE and family interview.

\section{ACKNOWLEDGEMENTS}

This work was supported by the Medical Research Council of Canada (HC, HS), the Alzheimer's Society of Canada (HC, HB), the FRSQ (Fonds de la Recherche en Santé du Québec) )HC, HB, HS), as well as the Alzheimer's Association (USA) (HC, HS). Dr. Chertkow is a chercheur-boursier clinicien, and Dr Schipper is a chercheur-boursier of the F.R.S.Q. (Fonds de la recherche en santé du Québec). We thank Shelley Solomon and Kate Hanratty for assistance in the preparation of this manuscript.

\section{REFERENCES}

1. Reisberg B, Ferris S. Diagnosis and assessment of the older patient. Hosp Community Psychiatry 1982; 33(2): 104-110.

2. Blackford RC, LaRue A. Criteria for diagnosing age-associated 
memory impairment: proposed revisions from the field. Dev Neuropsychol 1989; 5: 295-306.

3. Dawe B, Procter A. Concepts of mild memory impairment in the elderly and their relationship to dementia - a review. Int J Geriatr Psychiatry 1992; 7: 473-479.

4. Salthouse TA. Adult Cognition: An Experimental Psychology of Human Aging. New York: Springer Verlag, 1982.

5. Garcia C, Reding M, Blass J. Overdiagnosis of dementia. J Am Geriatr Soc 1981; 29: 407-410.

6. Ebly EM, Hogan DB, Parhad IM. Cognitive impairment in the nondemented elderly. Results from the Canadian Study of Health and Aging. Arch Neurol 1995; 52(6): 612-619.

7. Kral VA. Senescent forgetfulness: benign and malignant. Can Med Assoc J 1962; 86: 257-260.

8. Crook T, Bartus RT, Ferris SH, et al. Age-associated memory impairment: proposed diagnostic criteria and measures of clinical change: Report of a National Institute of Mental Helath Work Group. Dev Neuropsychol 1986; 2: 261-276.

9. Hughes $\mathrm{C}$, et al. A new clinical scale for the staging of dementia. Br J Psychiatry 1982; 140: 566-572.

10. Berg L. Clinical dementia rating (CDR). Psychopharmacol Bull 1988; 24(4): 637-639.

11. Levy R. Report of the working party of the International Psychogeriatric Association in collaboration with the World Health Organization: aging-associated cognitive decline [published erratum appears in Int Psychogeriatr 1994;6(2):133]. Int Psychogeriatr, 1994; 6(1): 63-68.

12. Petersen RC, Smith GE, Tangalos EG, Kokmen E, Ivnik RJ. Longitudinal outcome of patients with a mild cognitive impairment. Ann Neurol 1993; 34: 294-295.

13. Ritchie $\mathrm{K}$, et al. A typology of sub-clinical senescent cognitive disorder. Br J Psychiatry 1996; 168(4): 470-476.

14. Zaudig M. A new systematic method of measurement and diagnosis of mild cognitive impairment and dementia according to ICD-10 and DSM-III-R criteria. Int Psychogeriatr 1992; 4(Suppl. 2): 203219.

15. Petersen RC, et al. Mild cognitive impairment: clinical characterization and outcome [published erratum appears in Arch Neurol 1999;56(6):760]. Arch Neurol 1999; 56(3): 303-308.

16. Daly E, et al. Predicting conversion to Alzheimer's disease using standardized clinical information. Arch Neurol 2000; 57(5): 675680.

17. O'Connor DW. Mild dementia: a clinical perspective. In: Hippert FA, Brayne C, O'Connor DW, eds. Dementia and Normal Aging. Cambridge University Press: Cambridge. 1994;91-118.

18. Chertkow H. Mild memory loss in the elderly: can we predict development in dementia? Can J Neurol Sci 1998; 25(1): S1-S4.

19. Hanninen T, et al. A follow-up study of age-associated memory impairment: neuropsychological predictors of dementia. JAGS 1995; 43(9): 1007-1015.

19a. Hogan DB, Ebly EM. Predicting who will develop dementia in a cohort of Canadian seniors. Can J Neurol Sci 2000;27:18-24.

20. Morris J. Healthy brain aging in nonagenarians and centenarians. Neurobiol Aging 2000; 21(1S): S280.

21. Ritchie K, Touchon J. Mild cognitive impairment: conceptual basis and current nosological status [see comments]. Lancet 2000; 355(9199): 225-258.

22. Morris JC, et al. Very mild Alzheimer's disease: informant-based clinical, psychometric, and pathologic distinction from normal aging. Neurology 1991; 41(4): 469-478.

23. Tierney MC, et al. The prediction of Alzheimer's disease. The role of patient and informant perceptions of cognitive deficits. Arch Neurol 1996; 53(5): 423-427.

24. McGlone J, et al. Screening for early dementia using memory complaints from patients and relatives. Arch Neurol 1990; 47(11): 1189-1193.

25. Jorm A, et al. Do cognitive complaints either predict future cognitive decline or reflect past cognitive decline? A longitudinal study of an elderly community sample. Psychol Med 1997; 27(1): 91-98.

26. Schofield PW, et al. The validity of new memory complaints in the elderly. Arch Neurol 1997; 54(6): 756-759.
27. Chertkow HM, et al. Standard neuropsychological tests do not predict development of Alzheimer's disease in indivduals with "Age-associated Cognitive Decline". Can J Neurol Sci 1998; 25(Suppl 2): S27 (Abstract).

28. Fellows L, Chertkow H, Bergman H. Can clinical data predict progression to Alzheimer's disease in patients with mild memory impairment? Can J Neurol Sci 1998; 25(Suppl 2): S28 (Abstract).

29. Verret $\mathrm{L}$, et al. Disorientation to time as a predictor of progression to Alzheimer's disease for age-associated cognitive decline patients. Can J Neurol Sci 1999; 26(Suppl 1): S16.

30. (CSHA). Canadian Study of Health and Aging: Risk factors for Alzheimer's disease in Canada. Neurology 1994; 44: 2073-2080.

31. Graham JE, et al. Prevalence and severity of cognitive impairment with and without dementia in an elderly population. Lancet 1997; 349(9068): 1793-1796.

32. (APA). APA, Diagnostic and Statistical Manual of Mental Disorders, 4th ed.: DSM-IV. 4th ed. Washington, DC. 1994.

33. Gélinas I. Disability assessment in dementia of the Alzheimer's type. In: School of Physical and Occupational Therapy. McGill University: Montreal. 1995.

34. Gauthier,- L. Gelinas I. Development of a functional measure for persons with Alzhaeimer's disease: the disability assessment for dementia. Am J Occup Ther 1999;53:471-481.

35. Reisberg B. Functional assessment staging (FAST). Psychopharmacol Bull 1988; 24: 653-659.

36. Rosenman S. The validity of the diagnosis of mild dementia. Psychol Med 1991; 21(4): 923-934.

37. Erkinjuntti $\mathrm{T}$, et al. The effect of different diagnostic criteria on the prevalence of dementia. New Eng J Med 1997; 337(23): 16671674.

38. Wells C. Chronic brain disease: an overview. Am J Psychiatry 1978; 135: 1-12.

39. Clarfield AM. The reversible dementias: do they reverse? Ann Int Med 1988; 109(6): 476-486.

40. Clarfield AM, Foley JM. The American and Canadian consensus conferences on dementia: is there consensus? [see comments]. J Am Geriatr Soc 1993; 41(8): 883-886.

41. Skoog I, et al. A population-based study of dementia in 85-yearolds [see comments]. New Eng J Med 1993; 328(3): 153-158.

42. Evans DA, Funkenstein H, Albert MS, et al. Prevalence of Alzheimer's disease in a community population of older persons. JAMA1989; 262(18): 2551-2556.

43. Weytingh MD, Bossuyt PM, van Crevel H. Reversible dementia: more than $10 \%$ or less than $1 \%$ ? A quantitative review. J Neurology 1995; 242: 466-471.

44. Walstra GJ, Teunisse S, van Gool W, van Crevel H. Reversible dementia in elderly patients referred to a memory clinic. J Neurology 1997; 244: 17-22.

45. Geldmacher D, Whitehouse P. Evaluation of dementia. New Eng J Med 1996; 335(5): 330-336.

46. Geldmacher DS, Whitehouse PJ Jr. Differential diagnosis of Alzheimer's disease. Neurology 1997; 48(5 Suppl 6): S2-S9.

47. Kaye JA. Diagnostic challenges in dementia. Neurology 1998; 51(Suppl 1): S45-S52.

48. Royall DR, Polk M. Dementias that present with and without posterior cortical features: an important clinical distinction. J Am Geriatr Soc 1998; 46(1): 98-105.

49. (CSHA) C.S.o.H.a.A. Canadian Study of Health and Aging Working Group: study methods and prevalence of dementia. Can Med Assoc J 1994; 150: 899-913.

50. McKhann G, et al. Clinical diagnosis of Alzheimer's disease: report of the NINCDS-ADRDAwork group under the auspices of Health and Human Services Task Force on Alzheimer's Disease. Neurology 1984; 34: 939-944.

51. Black SE. Focal cortical atrophy syndromes. Brain Cogn 1996; 31(2): 188-229.

52. Neary D, et al. Neuropsychological syndromes in presenile dementia due to cerebral atrophy. J Neurol Neurosurg Psychiatry 1986; 49: 163-174.

53. Neary D. Non Alzheimer's disease forms of cerebral atrophy [editorial]. J Neurol Neurosurg Psychiatry 1990; 53(11): 929931. 
54. Gibb WR, et al. Cortical Lewy body dementia: clinical features and classification. J Neurol Neurosurg Psychiatry 1989; 52(2): 185192.

55. Snowdon J, Griffiths H, Neary D. Progressive language disorder associated with frontal lobe degeneration. Neurocase 1996; 2: 429-440.

56. Kertesz A, Davidson W, Fox H. Frontal behavioral inventory: diagnostic criteria for frontal lobe dementia. Can J Neurol Sci 1997; 24(1): 29-36.

57. Neary D, et al. Frontotemporal lobal degeneration. A concensus on clinical diagnostic criteria. Neurology 1998; 51(6): 1546-1554.

58. Chow TW, et al. Inheritance of frontotemporal dementia. Arch Neurol 1999; 56(7): 817-822.

59. Perry RJ, Hodges JR. Differentiating frontal and temporal variant frontotemporal dementia from Alzheimer's disease. Neurology 2000; 54(12): 2277-2284.

60. Rahman $\mathrm{S}$, et al. Specific cognitive deficits in mild frontal variant frontotemporal dementia. Brain 1999; 122(8): 1469-1493.

61. Miller BL, et al. Frontal lobe degeneration: clinical, neuropsychological, and SPECT characteristics. Neurology 1991; 41(9): 1374-1382.

62. Al-Asmi A, Chertkow H, Albrecht S, et al. Amyotrophic lateral sclerosis presenting as restricted cognitive impairment. In: American Neuropsychiatric Association meeting. Honolulu, USA. 1998.

63. Marsden CD. Neurological causes of dementia other than Alzheimer's disease. In: Burrows K, ed. Handbook of Studies on Psychiatry and Old Age. Elsevier Science Publishers B.V. 1984; 145-167.

64. Cummings JL, Victoroff JI. Noncognitive neuropsychiatric syndromes in Alzheimer's disease. Neuropsychiatry Neuropsychol Behav Neurol 1990; 3(2): 140-158.

65. Chui HC, et al. Criteria for the diagnosis of ischemic vascular dementia proposed by the State of California Alzheimer's Disease Diagnostic and Treatment Centers. Neurology 1992; 42: 473-480.

66. Rockwood K, et al. Diagnosis of vascular dementia: Consortium of Canadian Centres for Clinical Cognitive Research Consensus Statement. Can J Neurol Sci 1994; 21: 358-364.

67. Roman GC, et al. Vascular dementia: diagnostic criteria for research studies. Report of the NINDS-AIREN International Workshop. Neurology 1993; 43(2): 250-260.

68. Amar K, et al. The presence of leuko-araiosis in patients with Alzheimer's disease predicts poor tolerance to tacrine, but does not discriminate responders from non-responders. Age Ageing, 1997; 26(1): 25-29.

69. Gold M. Physostigmine and Alzheimer's disease [letter; comment]. Neurology 1997; 49(2): 642-643.

70. Corey-Bloom J, et al. Clinical features distinguishing large cohorts with possible $\mathrm{AD}$, probable $\mathrm{AD}$, and mixed dementia. J Am Geriatr Soc 1993; 41(1): 31-37.

71. Hachinski VC, Iliff LD, Zilhka E, et al. Cerebral blood flow in dementia. Arch Neurol 1975; 32: 632-637.

72. Rosen WG, Terry RD, Fuld PA, Katzman R, Peck A. Pathological verification of ischemic score in differentiation of dementia. Ann Neurol 1980; 7: 486-488.

73. Boller F, Lopez OL, Moossy J. Diagnosis of dementia: clinicopathologic correlations. Neurology 1989; 39(1): 76-79.

74. Snowdon DA, et al. Brain infarction and the clinical expression of Alzheimer's disease: the nun study. JAMA 1997; 277(10): 813817.

75. Forette F, et al. Prevention of dementia in randomised double-blind placebo-controlled Systolic Hypertension in Europe (Syst-Eur) trial [see comments]. Lancet 1998; 352(9137): 1347-1351.

76. Mayeux R, Stern Y, Spanton S. Heterogeneity in dementia of the Alzheimer's type: evidence of subgroups. Neurology 1985; 35(4): 453-461.

77. Mayeux R, Stern Y. Intellectual dysfunction and dementia in Parkinson's disease. In: Mayeux R, Rosen WG. eds. The Dementias. Raven Press: New York. 1983; 211-227.

78. McKeith IG, et al. Consensus guidelines for the clinical and pathologic diagnosis of dementia with Lewy bodies (DLB): report of the consortium on DLB international workshop. Neurology 1996; 47(5): 1113-1124.

79. Gomez-Tortosa E, et al. Clinical and quantitative pathologic correlates of dementia with Lewy bodies. Neurology 1999; 53(6): 1284-1291.

80. Verghese $\mathbf{J}$, et al. Validity of clinical criteria for the diagnosis of dementia with Lewy bodies. Neurology 1999; 53(9): 1974-1982.

81. McKeith IG, Perry EK, Perry RH. Report of the second dementia with Lewy body international workshop: diagnosis and treatment. Neurology 1999; 53(5): 902-905.

82. Lopez OL, et al. Accuracy of four clinical diagnostic criteria for the diagnosis of neurodegenerative dementias. Neurology 1999; 53(6): 1292-1299.

83. Litvan I, et al. Clinical research criteria for the diagnosis of progressive supranuclear palsy (Steele-Richardson-Olszewski syndrome): report of the NINDS-SPSP international workshop. Neurology 1996; 47(1): 1-9.

84. Pillon B, et al. Heterogeneity of cognitive impairment in progressive supranuclear palsy, Parkinson's disease, and Alzheimer's disease. Neurology 1986; 36(9): 1179-1185.

85. Johnson RT, Gibbs CJ Jr. Creutzfeldt-Jakob disease and related transmissible spongiform encephalopathies. New Eng J Med 1998; 339(27): 1994-2004.

86. Kretzschmar HA, et al. Diagnostic criteria for sporadic CreutzfeldtJakob disease. Arch Neurol 1996; 53(9): 913-920.

87. Zerr I. et al. Detection of 14-3-3 protein in the cerebrospinal fluid supports the diagnosis of Creutzfeldt-Jakob disease. Ann Neurol 1998; 43(1): 32-40.

88. Schneider JA, et al. Corticobasal degeneration: neuropathologic and clinical heterogeneity. Neurology 1997; 48(4): 959-969.

89. Kertesz A, et al. The pathology and nosology of primary progressive aphasia [see comments]. Neurology 1994; 44(11): 2065-2072.

90. Grimes DA, Lang AE, Bergeron CB. Dementia as the most common presentation of cortical-basal ganglionic degeneration. Neurology 1999; 53(9): 1969-1974.

91. Caine ED. Neuropsychology of depression: the pseudodementia syndrome. In: Grant I, Adams KM. eds. Neuropsychological Assessment of Neuropsychiatric Disorders. Oxford University Press: New York, 1986.

92. McAllister TW, Price TRP. Severe depressive pseudodementia with and without dementia. Am J Psychiatry 1982; 139: 626-628.

93. Reifler B, Larson E, Hanley R. Coexistence of dementia and depression in geriatric outpatients. Am J Psychiatry 1982; 139: 623-625.

94. Erkinjuntti T, et al. Accuracy of the clinical diagnosis of vascular dementia: a prospective clinical and postmortem neuropathological study. J Neurol Neurosurg Psychiatry 1988; 51: 10371044.

95. Erickson R, Howieson D. The clinician's perspective: measuring change and treatment effectiveness. In: L. Poon, ed. Clinical Memory Assessment of Older Adults. American Psychological Association: Washington, DC. 1986; 69-80.

96. Appell J, Kertesz A, Fisman M. A study of language functioning in Alzheimer's patients. Brain Lang 1982; 17: 73-91.

97. Lippa CF, Johnson R, Smith TW. The medial temporal lobe in dementia with Lewy bodies: a comparative study with Alzheimer's disease. Ann Neurol 1998; 43(1): 102-106.

98. McCartney JR. Physician's assessment of cognitive capacity: failure to meet the needs of the elderly. Arch Int Med 1986; 146: 177-178.

99. Sluss TK, Rabins P, Gruenberg EM, Reedman G. Memory complaints in community residing men. Gerontologist 1980; 20(20): 201-218.

100. Bolla-Wilson K, Bleeker M. Memory complaints - dementia or depression? Gerontologist 1986; 26: 142-149.

101. Rubin EH, et al. Very mild senile dementia of the Alzheimer's type. I. Clinical assessment. Arch Neurol 1989; 46(4): 379-382.

102. Fitz AG, Teri L. Depression, cognition, and functional ability in patients with Alzheimer's disease. J Am Geriatr Soc 1994; 42(2): 186-191.

103. Barberger-Gateau P, et al. Instrumental activities of daily living as 
a screening tool for cognitive impairment and dementia in elderly community dwellers. J Am Geriatr Soc 1992; 40(11): 1129-1134.

104. Huff FJ, et al. The neurologic examination in patients with probable Alzheimer's disease. Arch Neurol 1987; 44: 929-933.

105. Serby M, et al. Olfactory identification deficits in relatives of Alzheimer's disease patients. Biol Psychiatry 1996; 39(5): 375377.

106. Graves $\mathrm{AB}$, et al. Impaired olfaction as a marker for cognitive decline: interaction with apolipoprotein $\mathrm{E}$ epsilon4 status. Neurology 1999; 53(7): 1480-1487.

107. Galasko D, et al. Neurological findings in Alzheimer's disease and normal aging. Arch Neurol 1990; 47(6): 625-627.

108. Franssen E, et al. Cognition-independent neurologic symptoms in normal aging and probable Alzheimer's disease. Arch Neurol 1991; 48(2): 148-154.

109. Jenkyn L, Reeves A, Warner $T$, et al. Neurological signs in senescence. Arch Neurol 1985; 42: 1154-1157.

110. Huff F, Growdon J. Neurological abnormalities associated with severity of dementia in Alzheimer's disease. Can J Neurol Sci 1986; 13(4 Suppl): 403-405.

111. Lopez OL, et al. Extrapyramidal signs in patients with probable Alzheimer's disease. Arch Neurol 1997; 54(8): 969-975.

112. Folstein MF, Folstein SE, McHugh PR. "Mini-mental state": A practical method for grading the cognitive state of patients for the clinician. J Psychiatr Res 1975; 12(3): 189-198.

113. Siu A. Screening for dementia and investigating its causes (review). Ann Int Med 1991; 115(2): 122-132.

114. Tombaugh TN, McIntyre NJ. The Mini-Mental State Examination: a comprehensive review. J Am Geriatr Soc 1992; 40: 922-935.

115. Dick JPR, et al. Mini-Mental State Examination in neurological patients. J Neurology Neurosurg Psychiatry 1984; 47: 496-499.

116. Clark CM, et al. Variability in annual Mini-Mental State Examination score in patients with probable Alzheimer's disease: A clinical perspective of data from the Consortium to Establish a Registry for Alzheimer's Disease. Arch Neurol 1999; 56(7): 857862.

117. Grober E, Buschke HCHBS, Dresner R. Screening for dementia by memory testing. Neurology 1988; 38(6): 900-903.

118. Tuokko $\mathrm{H}$, et al. The Clock Test: a sensitive measure to differentiate normal elderly from those with Alzheimer's disease. J Am Geriatr Soc 1992; 40(6): 579-584.

119. Stahelin HB, Monsch AU, Spiegel R. Early diagnosis of dementia via a two-step screening and diagnostic procedure. Int Psychogeriatr 1997; 9(Suppl 1): 123-130.

120. Solomon PR, et al. A 7 minute neurocognitive screening battery highly sensitive to Alzheimer's disease. Arch Neurol 1998; 55(3): 349-355.

121. Huff FJ, et al. Cognitive deficits and clinical diagnosis of Alzheimer's disease. Neurology 1987; 37(7): 1119-1124.

122. Chui H, Zhang Q. Evaluation of dementia: a systematic study of the usefulness of the American Academy of Neurology's practice parameters. Neurology 1997; 49(4): 925-935.

123. Stern Y, et al. Diagnosis of dementia in a heterogeneous population. Arch Neurol 1992; 49(5): 453-460.

124. Clarfield M. Assessing dementia: the Canadian Consensus. Can Med Assoc J 1991; 144: 851-853.

125. Corey-Bloom J, et al. Diagnosis and evaluation of dementia. Neurology 1995.;45(2): 211-218.

126. Patterson CJ, et al. Canadian Consensus Conference on Dementia: a physician's guide to using the recommendations [see comments]. Can Med Assoc J 1999.;160(12): 1738-1742.

127. Helkala EL, et al. Different patterns of cognitive decline related to normal or deteriorating EEG in a 3-year follow-up study of patients with Alzheimer's disease. Neurology 1991; 41(4): 528532.

128. Hammerstrom DC, Zimmer B. The role of lumbar puncture in the evaluation of dementia: the University of Pittsburgh study. J Am Geriatr Soc 1985; 33: 397-400.

129. Hsich G, et al. The 14-3-3 brain protein in cerebrospinal fluid as a marker for transmissible spongiform encephalopathies [see comments]. New Eng J Med 1996; 335(13): 924-930.

130. (AAN), Quality Standards Subcommittee of the Americal
Academy of Neurology. Practice parameter for diagnosis and evaluation of dementia (Summary statement). Neurology 1994; 44: 2203-2206.

131. Rossor MN. Management of neurological disorders: dementia. J Neurol Neurosurg Psychiatry 1994; 57: 1451-1456.

132. Small GW, et al. Diagnosis and treatment of Alzheimer's disease and related disorders: consensus statement of the American Association for Geriatric Psychiatry, the Alzheimer's Association and the American Geriatrics Society. JAMA 1997; 278(16): 1363-1371.

133. Gordon M, Freedman M. Evaluating dementia: What price testing? Can Med Assoc J 1990. 142(12): 1367-1370.

134. Gauthier S. Costs of diagnostic procedures. In: Wimo A, Jonsson B, Karlsson G, Winblad B, eds. Health Economics of Dementia. Chichester: John Wiley and Sons 1998; 269-275.

135. Patterson C, Gauthier S, Bergman $\mathrm{H}$, et al. The recognition, assessment and management of dementing disorders: conclusions from the Canadian Consensus Conference on Dementia. Can Med Assoc J 1999; 160(suppl 12): S1-S15.

136. Creasey $\mathrm{H}$, et al. Quantitative computed tomography in dementia of the Alzheimer's type. Neurology 1986; 36(12): 1563-1568.

137. Freter $S$, et al. Prevalence of potentially reversible dementias and actual reversibility in a memory clinic cohort. Can Med Assoc J 1998; 159(6): 657-662.

138. Willmer J, et al. The usefulness of CT scanning in diagnosing dementia of the Alzheimer's type. Can J Neurol Sci 1993; 20(3): 210-216.

139. de Leon MJ, et al. The radiologic prediction of Alzheimer's disease: the atrophic hippocampal formation. AJNR Am J Neuroradiol 1993; 14(4): 897-906.

140. Kidron D, et al. Quantitative MR volumetry in Alzheimer's disease. Topographic markers and the effects of sex and education. Neurology 1997; 49(6): 1504-1512.

141. Jack C, et al. Prediction of AD with MRI-based hippocampal volume in mild cognitive impairment. Neurology 1999; 52(7): 1397-1403.

142. Murtha S, et al. Mild cognitive impairment and the neuroanatomical changes associated with assessment of progression to dementia. Neurobiol Aging, 2000; 21(Suppl 1): S29.

143. Steingart A, et al. The significance of white matter lucencies on CT scan in relation to cognitive impairment. Can J Neurol Sci 1986; 13(4 Suppl): 383-384.

144. Steingart A, et al. Cognitive and neurologic findings in demented patients with diffuse white matter lucencies on computed tomographic scan (leuko-araiosis). Arch Neurol 1987; 44(1): 3639.

145. Inzitari D. Age-related white matter changes and cognitive impairment [editorial; comment]. Ann Neurol 2000; 47(2): 141143.

146. Jagust WJ, Budinger TF, Reed BR. The diagnosis of dementia with single photon emission computed tomography. Arch Neurol 1987; 44(3): 258-262.

147. Johnson KA, et al. Preclinical prediction of Alzheimer's disease using SPECT. Neurology 1998; 50: 1563-1571.

148. Powers WJ, et al. Blinded clinical evaluation of positron emission tomography for diagnosis of probable Alzheimer's disease. Neurology 1992; 42: 765-770.

149. Bergman H, et al. HM-PAO (CERETEC) SPECTbrain scanning in the diagnosis of Alzheimer's disease. J Am Geriatr Soc 1997; 45(1): 15-20.

150. Jagust W, et al. Single-photon emission computed tomographic perfusion imaging in autopsy-diagnosed dementia. J Neuroimaging 1993; 3: 93-99.

151. Geaney D, Abouh-saleh M. The use and applications of singlephoton emission computerised in tomography dementia. Br J Psychiatry, 1990; 157(Suppl 9): 66-75.

152. Johnson KA, Holman L, Rosen TJ. Iofetamine, I 123 single photon emission computed tomography is accurate in the diagnosis of Alzheimer's disease. Arch Int Med 1990; 150: 752-756.

153. Black SE. Can SPECT predict the future for mild cognitive impairment? Can J Neurol Sci 1999; 26: 4-6. 


\section{LE JOURNAL CANADIEN DES SCIENCES NEUROLOGIQUES}

153a. Johnson KA, Jones K, Holman BL, et al. Preclinical prediction of Alzheimer's disease using SPECT. Neurology 1998;50:15631571.

154. McKelvey R, et al. Lack of prognostic significance of SPECT abnormalities in non-demented elderly subjects with memory loss. Can J Neurol Sci 1999; 26: 23-28.

155. Kennard M. Diagnostic markers for Alzheimer's disease. Neurobiol Aging. 1998; 19(2): 131-132.

155a. Galasko, D. CSF tau and AB42: logical biomarkers for Alzheimer's disease. Neurobiol Aging 1998 ;19(2): 117-119.

156. Schipper HM, Chertkow H, Mehindate K, et al. Evaluation of heme oxygenase-1 levels as a systemic biological marker of sporadic AD. Neurology 2000;54:1297-1304.

157. Mayeux R, et al. Utility of the apolipoprotein E genotype in the diagnosis of Alzheimer's disease. Alzheimer's Disease Centers Consortium on Apolipoprotein E and Alzheimer's Disease. New Eng J Med 1998; 338(8): 506-511.

158. Corder EH, et al. Gene dose of apolipoprotein E type 4 allele and the risk of Alzheimer's disease in late-onset families. Science 1993; 261(5123): 921-923.

159. Farlow MR. Alzheimer's disease: clinical implications of the apolipoprotein E genotype. Neurology 1997; 48(Suppl 6): S30-S34. 